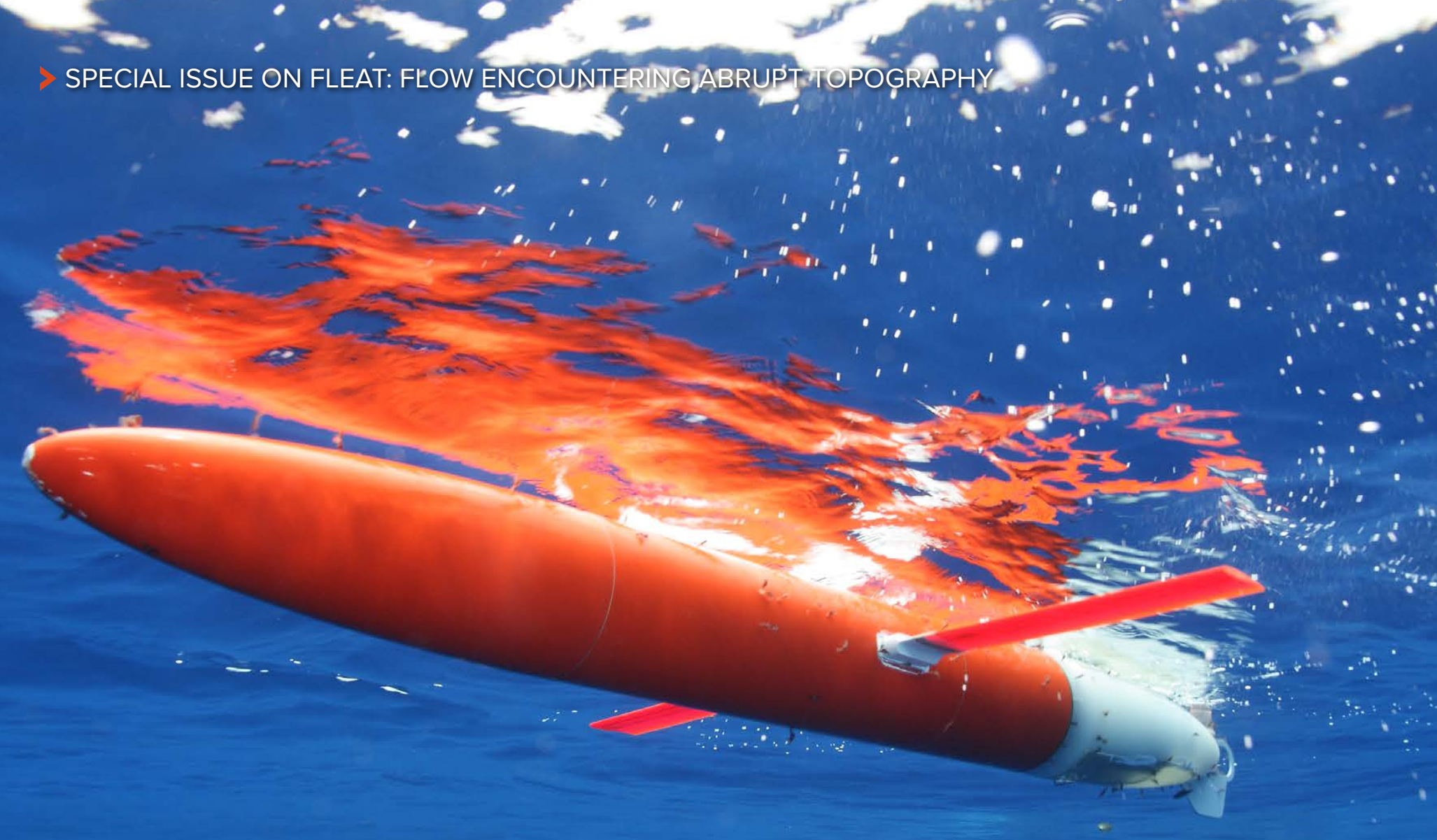

\title{
UNDERSTANDING VORTICITY CAUSED BY FLOW PASSING AN ISLAND
}

By Daniel L. Rudnick, Kristin L. Zeiden, Celia Y. Ou, T.M. Shaun Johnston, Jennifer A. MacKinnon, Matthew H. Alford, and Gunnar Voet 
ABSTRACT. This article presents a pedagogical approach toward understanding vorticity generated in flow past an island. The ubiquity of eddies in the ocean motivates the use of vorticity to quantify their rotation, and we define two kinds of vorticity: relative vorticity, that is, the vorticity of an eddy relative to Earth, and planetary vorticity, Earth's spin relative to local vertical. The ratio of relative to planetary vorticity is the Rossby number, Ro, a useful normalized measure of vorticity. Vorticity may be created in flow past an island as the alongshore current at the coast is forced to zero by friction. Observations from the Flow Encountering Abrupt Topography (FLEAT) program, including those from satellites, underwater gliders, ship surveys, and moorings, are used to measure vorticity as forced when the North Equatorial Current collides with the northern tip of Palau. The observations include time means over years, with Ro about 0.3 at horizontal length scales of tens of kilometers and snapshots of Ro as large as 30 from eddies of diameter $1 \mathrm{~km}$. Vorticity can be broad-banded in time, with strong westward flow causing vorticity at frequencies as high as semidiurnal. Implications of this wide range of scales in vorticity are discussed in the conclusion.

IN PLAIN WORDS. This article starts with a pedagogical introduction to vorticity, the technical term for the swirliness of a fluid. Vorticity may be generated by flow past an island, as friction slows the current near the coast. Observations from FLEAT, including those from satellites, underwater gliders, ship surveys, and moorings, are used to measure vorticity as forced when the North Equatorial Current encounters the northern tip of Palau. Oceanographers study vorticity because it is an essential property of the ocean's turbulent flow, especially important to the distribution of energy in the ocean.

\section{INTRODUCTION}

If one observes the flow of almost any fluid, the most evident features are swirls, or as we call them in oceanography, eddies. These eddies can range in size from the scales of turbulence, measured in centimeters, to the great rings of the Gulf Stream that may be hundreds of kilometers in diameter. One of the ways eddies are generated in the ocean is by friction when currents flow around topography. This process was a target of the Flow Encountering Abrupt Topography (FLEAT) experiment. A first step toward describing this process is to measure the strength of these eddies.

Vorticity is the measure of eddies that fluid dynamicists have used for over 100 years. The vorticity of an eddy with a rotation rate of $\omega$, measured in radians per second, would be twice the rotation rate, or $2 \omega$. This rotation rate has a sign, as eddies can rotate in either direction. We consider eddies that rotate in the same direction as Earth to be cyclonic and to have a positive rotation rate, and those that rotate in the opposite direction to be anticyclonic with a negative rotation rate.
In the Northern Hemisphere, cyclonic is counterclockwise and anticyclonic is clockwise. Cyclonic rotation is clockwise in the Southern Hemisphere, as the sense of Earth's rotation is opposite to vertical south of the equator. The word cyclone has been used for over one hundred years to describe intense atmospheric storms, direction in both hemispheres.

A casual glance at a turbulent fluid flow will reveal eddies of a range of sizes rotating at various rates. Defining vorticity for such a flow requires knowledge of the velocity as a function of position. Considering a two-dimensional horizontal flow, the vorticity is defined as

$$
\zeta=\frac{\partial v}{\partial x}-\frac{\partial u}{\partial y},
$$

where eastward and northward position are $x$ and $y$, and eastward and northward velocity are $u$ and $v$. An eddy rotating just like a bicycle wheel, in what is called solid body rotation, does have the property that its vorticity is twice the rotation rate $\zeta=2 \omega$. So, given observations of horizontal velocity, we now have a measure almost all of which rotate in the cyclonic of vorticity, the swirliness of a fluid.

A natural measuring stick for vorticity is given by Earth's rotation. If Earth were flat like an old-fashioned record turntable, its vorticity would just be twice its rotation rate, typically written as capital omega $(\Omega)$. But Earth is a sphere, and the rotation that matters for most ocean flows is that in the radial direction at any location (vertical for a person standing on Earth). The planetary vorticity is then

$$
f=2 \Omega \sin \theta,
$$

where $\theta$ is latitude and $f$ is the Coriolis parameter, which gives the frequency of a parcel of water freely oscillating on the surface of the rotating Earth. The Coriolis parameter is signed, positive in the Northern Hemisphere and negative in the Southern Hemisphere.

Now we have two kinds of vorticity, the planetary vorticity $f$ and the vorticity of the fluid relative to Earth, the relative vorticity $\zeta$. The ratio defined by the relative vorticity divided by the planetary vorticity gives a nondimensional value of the strength of an eddy. This nondimensional value is called the Rossby number:

$$
\mathrm{Ro}=\frac{\zeta}{f} .
$$

Quantifying vorticity using Ro helps to interpret the strength of an eddy. A very small Ro, where the relative vorticity is much weaker than the planetary vorticity, is typical of the general circulation that characterizes flow filling ocean basins. A very high Ro, where relative vorticity is many times as large as planetary vorticity, is typical of strong atmospheric cyclones, and can also be seen in the most rapidly rotating eddies we observed in FLEAT. Flows with absolute values of Ro near unity are especially interesting, as their dynamics depend on whether the eddy is rotating in the same or in the opposite direction as Earth. In the following, vorticity is always normalized as in Equation 3 to be the nondimensional Ro.

How do we get eddies with vorticity? It is a well-known physical principle that bodies in motion (in this case rotating) 
tend to stay in motion unless forced. The inverse is also true: bodies without rotation do not impulsively start rotating. A force must be applied to a flow to generate rotation and give it vorticity. One way is through the force of friction. Consider a current passing by a wall. Away from the wall, the current is moving with a uniform velocity, $U$. Near the wall, friction forces the current to slow down until the velocity becomes zero directly at the wall. We call the region over which the velocity goes from $U$ to zero the boundary layer. The change in velocity across the boundary layer generates vorticity, as in Equation 1. Now, imagine there is a sharp turn in the boundary. If the current has too much momentum to follow the turn, the boundary layer will peel away, and the vorticity will cause the current to form a rotating eddy downstream. This process is what occurs as a flow passes around an island.

The FLEAT experiments took place at the island of Palau, which has a special location in the circulation of the western north Pacific Ocean (Figure 1). Typically, the North Equatorial Current (NEC) heads westward, hitting the northern tip of Palau. The NEC is partially blocked, and friction may create eddies that we can quantify using vorticity through the measure of Ro. During El Niño years, especially as the El Niño is waning, this flow may be reversed. We had the unusual fortune to have FLEAT take place during one of the strongest El Niños of the last few decades, so the NEC did not flow
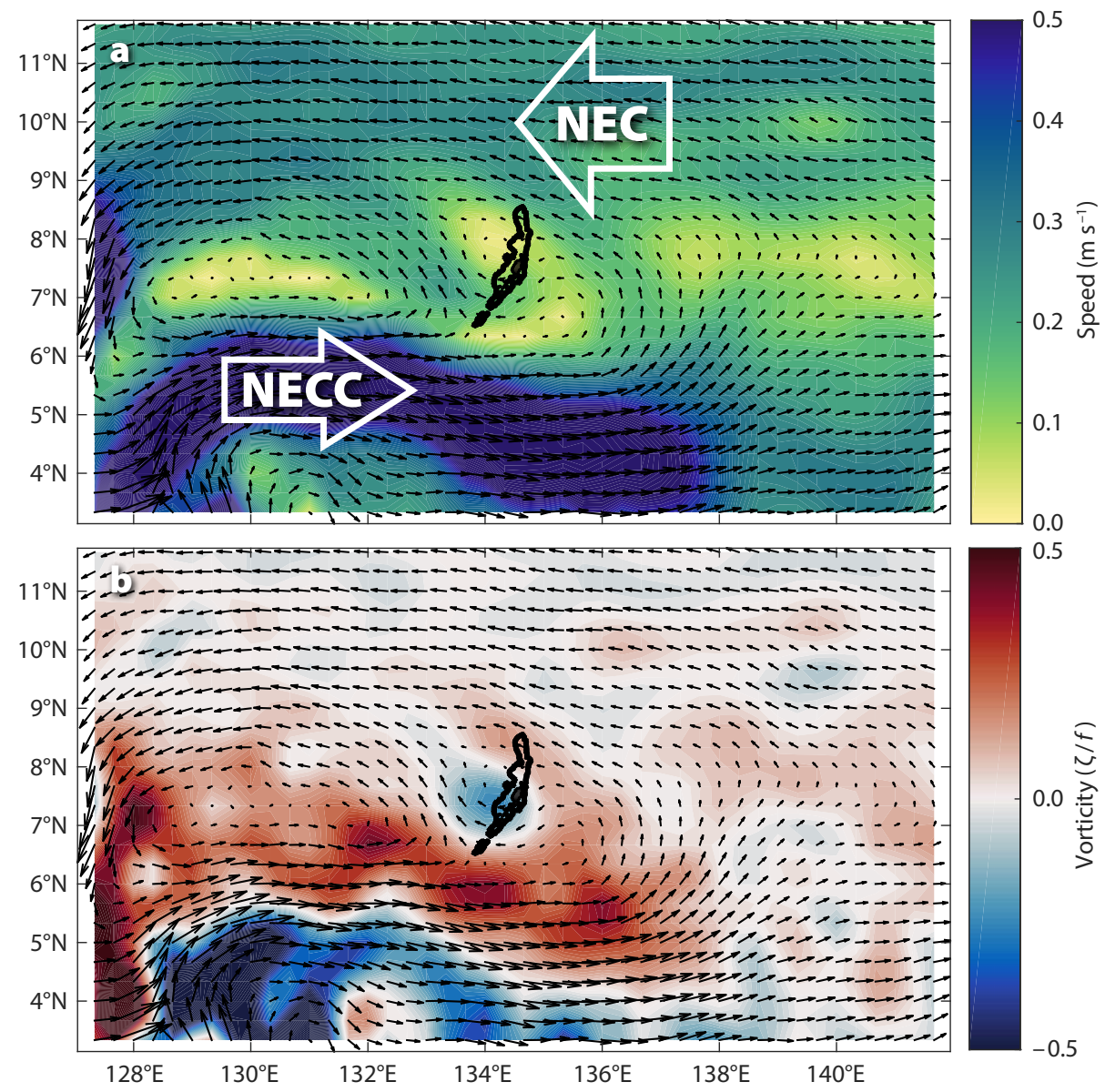

FIGURE 1. Current speed (a) and vorticity (b) at the ocean surface near Palau averaged over the period 2015-2018 according to the satellite product Ocean Surface Current Analysis (OSCAR). The current velocity is indicated by black arrows. The black contour outlines the 1,000 m isobath around Palau, and the filled black contour is the Palau island chain above sea level. The westward North Equatorial Current (NEC) lies to the north of Palau, while the eastward North Equatorial Countercurrent (NECC) lies to the south. A region of reduced current speed and negative vorticity can be seen to the west of Palau, indicative of an island-scale wake. consistently westward. Tides and internal waves also cause the flow to change direction and may be especially important close to the island, where eddies that are the smallest in size but the most rapidly rotating, are generated. The combination of tidal forcing and large-scale currents encountering an island cause the eddies we observed during FLEAT.

\section{OBSERVATIONS OF VORTICITY}

We used a variety of methods to observe vorticity, each especially well suited for a particular range of time and length scales. At the largest scales, satellite observations allow measurement of vorticity at the sea surface. To measure the flow before and after an island encounter, we deployed Spray underwater gliders for repeated sections on either side of the Palau ridge. Ship surveys at different resolutions revealed the detailed structure of eddies on horizontal length scales of tens of kilometers down to hundreds of meters. An array of moorings measuring velocities allowed calculation of time series of vorticity. These observations of vorticity are each discussed below.

A large-scale view of surface currents is provided by the satellite product Ocean Surface Current Analysis (OSCAR; Figure 1). OSCAR uses satellite observations of sea surface height, wind, and temperature to estimate surface currents obeying geostrophic and wind-driven dynamics. The NEC flows westward north of Palau (Schönau and Rudnick, 2015), and the eastward North Equatorial Countercurrent (NECC) is south of Palau. The strongest vorticity is on either side of the powerful NECC jet as it emerges from the western boundary. Ro is high due to large velocity gradients on either side of the jet, and because the planetary vorticity approaches zero toward the equator. FLEAT was focused on the vorticity caused by the NEC and the NECC passing the island on its north and south ends. This paper addresses the north end of Palau where a tongue of high vorticity (Ro $\sim 0.1$ in OSCAR) appears in the wake of the island on the southern 
flank of the NEC, and where we had the most observations. A feature of note is the mean northward flow east of Palau, which was influenced by the breakdown of the El Niño in spring 2016. At that time, warm water sloshed westward as trade winds reestablished themselves, causing the NECC to head anomalously northward, and bringing rapid warming to Palau (Schönau et al., 2019, and Andres et al., 2019, both in this issue).

Spray underwater gliders (Sherman et al., 2001; Rudnick, 2016) were deployed on either side of the Palau ridge to measure incident flow and the vorticity wake as the flow passes the island (Zeiden et al., 2019; Figure 2). A series of glider missions were sustained during October 2015-January 2018, while the gliders profiled from the surface to $1,000 \mathrm{~m}$, completing a cycle in $6 \mathrm{hr}$ and covering $5 \mathrm{~km}$ over ground in that time. Nearly 200 sections were completed on the two meridional lines at $134.25^{\circ} \mathrm{E}$ and $135^{\circ} \mathrm{E}$ between $7.75^{\circ} \mathrm{N}$ and $9.0^{\circ} \mathrm{N}$ through repeated missions that typically lasted 100 days. Each glider was equipped with a conductivity, temperature, depth instrument (CTD) to measure pressure, temperature and depth, and an acoustic Doppler current profiler (ADCP) to measure velocity as a function of depth.

A central goal was to measure the time mean velocity and vorticity before and after the NEC's encounter with the island. To accomplish this goal, the periods of incident westward current on the eastern section were selected to create an average on both sections (Zeiden et al., 2019). Westward flow occurred during about $60 \%$ of the glider sections, with $30 \%$ eastward flow, and $10 \%$ neither eastward nor westward. The effect of the island blocking the flow is apparent in the $1,000 \mathrm{~m}$ depth-average current (Figure 2e). The incident westward flow on the east side of the island has relatively weak primarily positive vorticity in the upper $100 \mathrm{~m}$, consistent with the NEC being stronger to the north (Figure 2b,d). After passing the island, the mean vorticity in the wake, on the west side, peaks at over 0.3 in the upper $100 \mathrm{~m}$ (Figure 2a). On the western line (Figure 2c), a weak eastward return flow is seen near $8.4^{\circ} \mathrm{N}$, then another region of westward flow near $8.6^{\circ} \mathrm{N}$. This southern region of westward flow, which may be influenced by a gap in the ridge, causes a region of persistent negative vorticity. Below $100 \mathrm{~m}$, the incident vorticity is weak at less than 0.1 and generally positive, with regions of negative vorticity. In the wake, on the west side, the deep vorticity is a weaker extension of the near-surface velocity, with a slight tendency for the bands of vorticity to slope downward to the south. In summary, a persistent wake is apparent in the mean, making clear that the island is imparting vorticity to the flow through friction. An open question, addressed below, is the structure and forcing of the many eddies that are averaged to create the mean measured by gliders.

Mesoscale current patterns were observed over a wide area during a four-day survey on R/V Roger Revelle in October 2015. Currents were measured with the ship's Hydrographic Doppler Sonar System (Pinkel, 2012), while density was measured using SeaSoar, a towed vehicle equipped with a CTD. During this period of eastward flow, the upstream Ro is about 0.5 , but in the wake, Ro increases
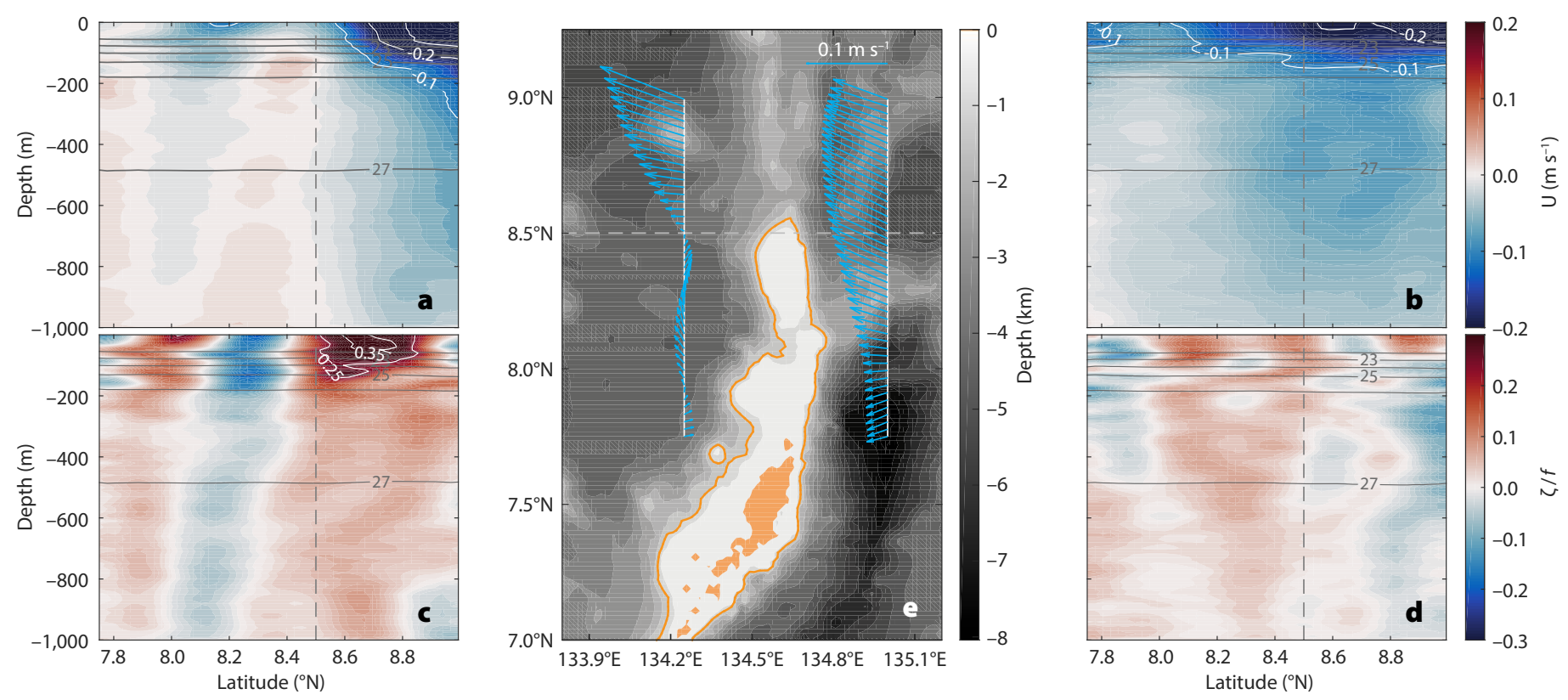

FIGURE 2. Eastward velocity (a, b, top left and right panels) and vorticity (c, d, bottom left and right panels) as a function of latitude and depth on the west (a, c) and east (b, d) side of the ridge, and 1,000 m depth-mean velocity (e) measured by Spray underwater gliders, averaged over periods of westward incident flow. Potential density contours are gray ( $a, b, c, d)$. The orange contour line in panel e is the 1,000 m isobath around Palau, and the filled orange contour is the Palau island chain above sea level. The incident westward flow on the eastern line (d) has relatively weak vorticity (b) but is generally positive in the upper $100 \mathrm{~m}$. Vorticity is markedly stronger on the western, lee side (a), and a mean vorticity of greater than 0.3 is established in the wake of the island. Adapted from Zeiden et al. (2019) 
as eddies are generated by the flow past topography. Northeastward flow past the north point produced an anticyclonic wake eddy with Ro $\sim-1$ and a $20 \mathrm{~km}$ diameter at $8.6^{\circ} \mathrm{N}$, which is about half the size of the submerged shallow reef within the $100 \mathrm{~m}$ isobath (Figure 3). Meanwhile, eastward flow through the gap produced two counter-rotating eddies at $8.2^{\circ} \mathrm{N}$ with Ro magnitudes reaching 3 and diameters of about $20 \mathrm{~km}$. The observed Ro in this snapshot is up to a factor of 10 larger than the two-year mean measured by the gliders, but about a factor of 10 smaller than obtained with the finer surveys presented below.

Very close to the northern and southern tips of Palau, small-scale $(\sim 1 \mathrm{~km})$ wake eddies are observed. Figure 4 shows an example from the northern end of Palau (MacKinnon et al., 2019), during a period of relatively weak low-frequency flow. Within a few kilometers of the point, the ocean floor rises steeply, and tidal currents become strong in the shallow water. At the $400 \mathrm{~m}$ isobath, the tidal excursion (the distance traveled by a parcel advecting back and forth with the tide) is $4-8 \mathrm{~km}$, which is large compared to the width of this point (Figure 4a). The tidal currents are of similar strength to the mean flow in the NEC. Hence, the total current sloshes back and forth past the island tip with the direction depending on how the tidal and mean flow currents align at any given time, producing

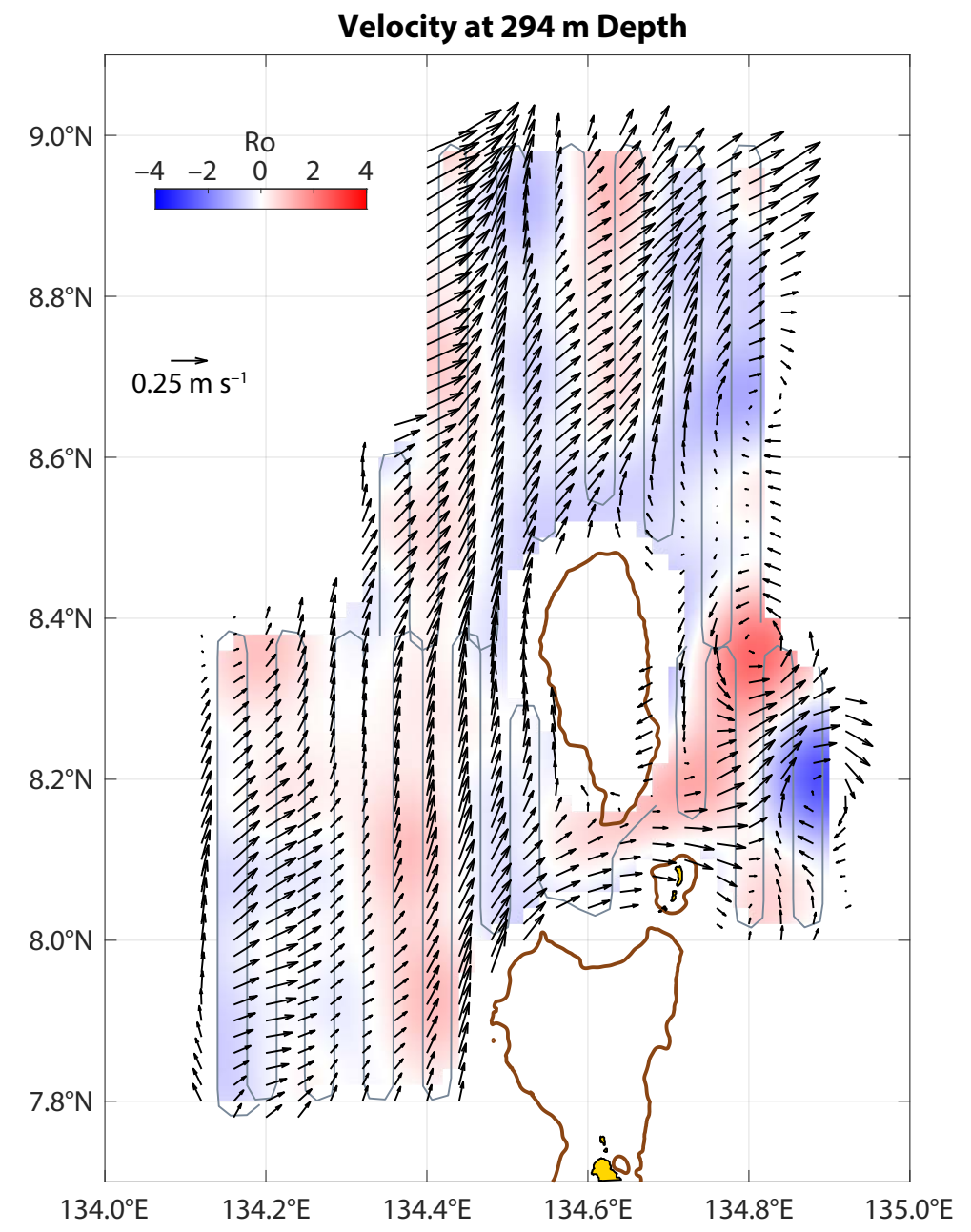

FIGURE 3. Ship-based velocity measurements at $294 \mathrm{~m}$ depth in October 2015 show eastward flow produces a wake of Ro $\sim-1$ near the north point and two counter-rotating eddies in the gap with the magnitude of Ro reaching 3. Upstream magnitudes of Ro are about 0.5 . The ship track is shown in gray. The bathymetry at $100 \mathrm{~m}$ is contoured in brown, and land is yellow outlined in black at the bottom of the panel. The scale vector shows $0.25 \mathrm{~m} \mathrm{~s}^{-1}$ eastward velocity.

eddies of different vorticity signs, and strengths, on either side of the point.

The data shown in Figure 4 were collected in 2016 with $\mathrm{R} / \mathrm{V}$ Revelle. The ship carried out repeat occupations of a radiator-style survey pattern, measuring ocean currents with the Doppler sonar. Ocean currents (vector arrows) and Ro (color) at three different depths highlight the complexity of small-scale vorticity production. At the time of this survey (conducted from east to west), the tidal currents are switching from eastward to westward. In Figure 4c, a negative vorticity, anticyclonic (purple color) eddy is visible to the east of the point, created during the previous period of eastward currents. As the currents switch to flow westward, we observe the creation of a strong cyclonic eddy (orange colors) to the west of the point. Ro is $20-30$ for these $\sim 1 \mathrm{~km}$ features.

A sloping ridge at the northern point of the island affects vorticity at different depths (Figure $4 b-d$ ). The two eddies discussed in the previous paragraph are strongest at $90 \mathrm{~m}$ (Figure 4c), as currents at this depth accelerate around and over the ridge extending northward from the island. Shallower, at $30 \mathrm{~m}$ (Figure 4b), vorticities of the same signs are visible (cyclonic to the west, anticyclonic to the east) but with muted amplitude. Deeper, at $225 \mathrm{~m}$ (Figure 4d), the westward flow on the west side of the ridge does not cause strong vorticity near the island, while the anticyclonic eddy to the east visibly tilts with depth. Similar phenomenology is also visible at Peleliu Island at the southern tip of Palau (Johnston et al., 2019, in this issue), where a combination of steady flow and tidal currents produce $1 \mathrm{~km}$ scale anticyclonic eddies with Ro $\sim-50$.

The observations detailed above show that the strength and structure of vorticity can be different depending on the spatial scales being measured. To fully understand vorticity, we must also consider that geophysical flows have a variety of behaviors across different timescales. Velocity measurements from fixed 
moorings around the northern tip of Palau show how the strength of vorticity depends on the frequency being measured (Figure 5). The moorings were deployed from May 2016 to April 2017. Velocity was measured as a function of depth using an array of ADCPs, and here we focus on the upper $60 \mathrm{~m}$ where flow is most energetic (Figure 2). The ADCPs sampled at a minimum rate of once per 16 minutes, so the resolved timescales range from hours to months. The moorings were deployed in a triangle configuration roughly $6 \mathrm{~km}$ in scale (Figure 5a), and vorticity was calculated from horizontal gradients determined by fitting a plane to the velocity measurements at each time step.

The full time series of velocity and vorticity show how low-frequency swift cur- rents (at periods of weeks to months) are accompanied by strong vorticity due to the topographic drag imposed by the island (Figure 5b,c). This is most clearly evident in a three-month period from November 2016 to January 2017, when the flow was westward at about $0.5 \mathrm{~m} \mathrm{~s}^{-1}$ and Ro was nearly 5. Similar periods of westward flow (i.e., September 2016 and March 2017) were weaker and had lower average values of Ro. This relationship can be explained by a simple model of vorticity generated by friction. The source of vorticity in the wake is the gradient in velocity over the boundary layer (Roshko 1954). Because the value of velocity right at the boundary is zero, this gradient is directly proportional to the velocity just outside the boundary layer. Therefore, when the current increases, the vorticity increases as well.

Another important observation is less well understood: the vorticity magnitude of high-frequency motions increases when the low-frequency currents are strongest. While this relationship is apparent by eye in the full vorticity time series, a scalogram of vorticity at different frequencies and as a function of time shows the relationship explicitly (Figure 5d). Most notably, the period of westward flow highlighted above coincides with increases in vorticity variability across a wide range of frequencies. This suggests that the vorticity generated is broad-band, but there are clear peaks at the semidiurnal and diurnal tidal frequencies, as well as the inertial frequency. The velocity at the edge of the boundary layer comprises a super-
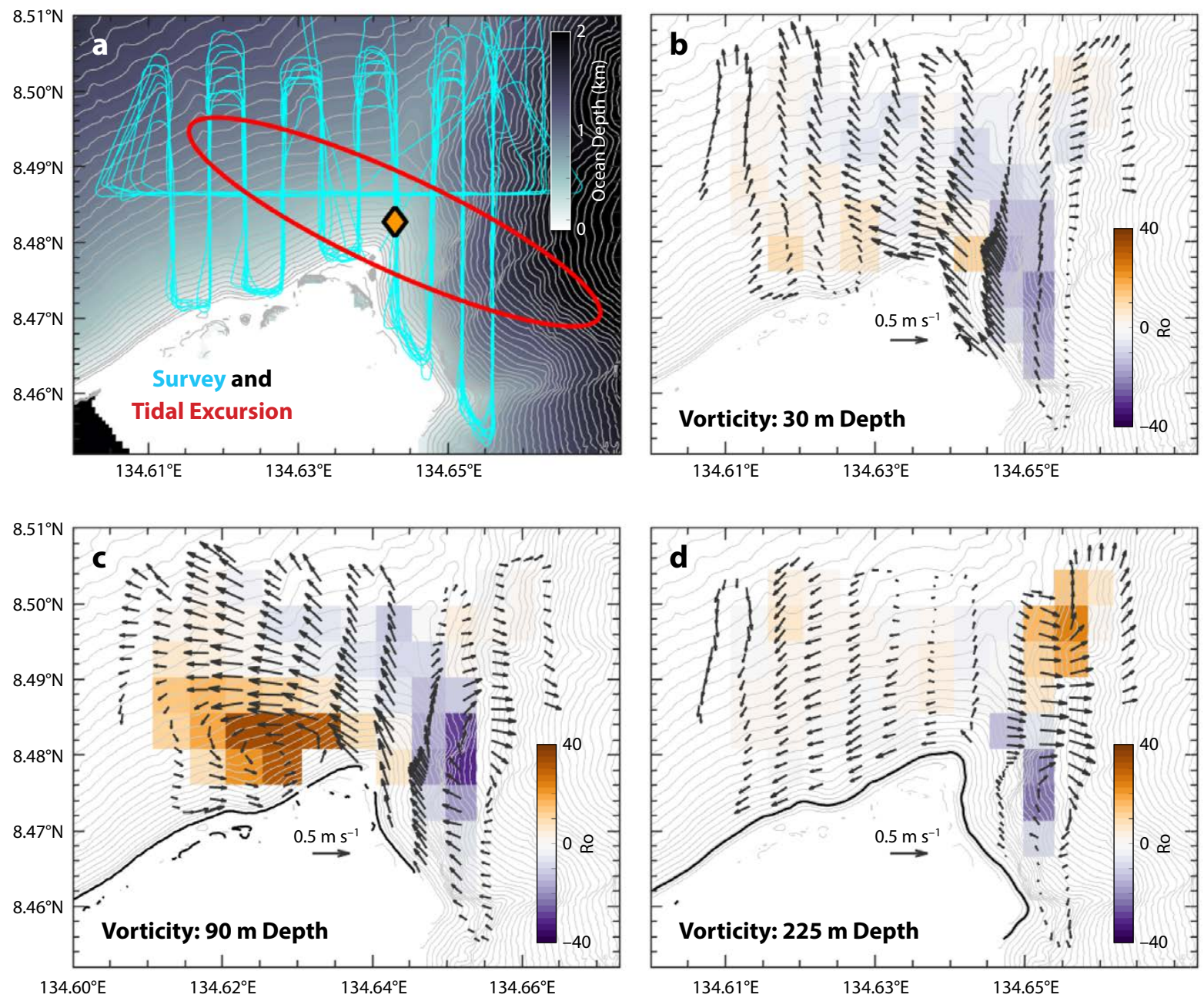

FIGURE 4. Vorticity and velocity measured during a fine-scale ship survey (a) conducted by R/V Revelle in June 2016 (cyan). The average tidal excursion (red ellipse) was estimated by a 10-month mooring record at the location of the orange diamond. Velocity vectors and vorticity (Ro, color) are shown at $30 \mathrm{~m}$ (c), at $90 \mathrm{~m}$ (d), and at $225 \mathrm{~m}$ (e) depths. Adapted from MacKinnon et al. (2019) 
position of the low-frequency flow and tidal currents. If the period of eddy shedding induced by the total current speed is much longer than a tidal period, eddies will instead be released when the flow wanes with the tide. In other words, when the low-frequency flow increases in magnitude, the vorticity generated across the boundary increases but eddies are shed at higher frequencies that exist in the flow. This process is explored more fully by MacKinnon et. al. (2019), from which Figure 4 is reproduced, and in Johnston et al. (2019, in this issue).

\section{CONCLUSION}

The observations of vorticity off Palau presented here span temporal scales from those of tides to those lasting several years, and spatial scales from hundreds of meters to hundreds of kilometers. To our knowledge, the FLEAT observations of vorticity caused by flow past an island are the most extensive ever collected. Averaged over two years as measured by underwater gliders, the flow in the wake of westward flow past Palau exhibits Ro $=0.3$ about $40 \mathrm{~km}$ downstream of the northern point (Figure 2). This mean vorticity is the result of averaging over many eddies that are generated near the point. In snapshots from ship surveys, Ro approaches 4 in eddies with radii of kilometers (Figure 3), and even smaller eddies with radii of $500 \mathrm{~m}$ can show Ro as large as 20-30 (Figure 4). Results from moorings suggest that the highest vorticities occur during periods of strong westward flow, when vorticity at frequencies at least up to the semidiurnal tide is elevated (Figure 5). This wide range of resolved scales is what makes the FLEAT data set unique for understanding vorticity.

The large vorticities observed off Palau can be contrasted to what is typically observed in the open ocean away from topography. At length scales of order $1-10 \mathrm{~km}$, the distribution of vorticity in the open ocean is observed to be positively skewed, with the largest Ro values near an absolute value of one (Rudnick, 2001; Shcherbina et al., 2013). This prev- alence of positive vorticity is a result of the instability of flows with Ro more negative than -1 . The eddies observed off Palau are fundamentally different in that they are directly forced by friction as flow passes the island. This strong, direct forcing causes rapidly rotating eddies with observed vorticities of both signs and Ro magnitudes as large as about 30. These most rapidly rotating eddies were observed upon generation, before evolving toward lower Ro as they were advected downstream. FLEAT achieved its goal of observing especially strong eddies caused by friction as flow passed an island.

Oceanographers care about vorticity because it is an essential property of turbulent flow. Turbulence is notoriously difficult to define, so it is often described as having a list of properties, with vorticity always in the list (Tennekes and Lumley, 1972). A central idea is that there is a cascade of energy, with forcing at large scales causing energy to move to ever smaller scales until the flow is dissipated at a length scale of about one mil-
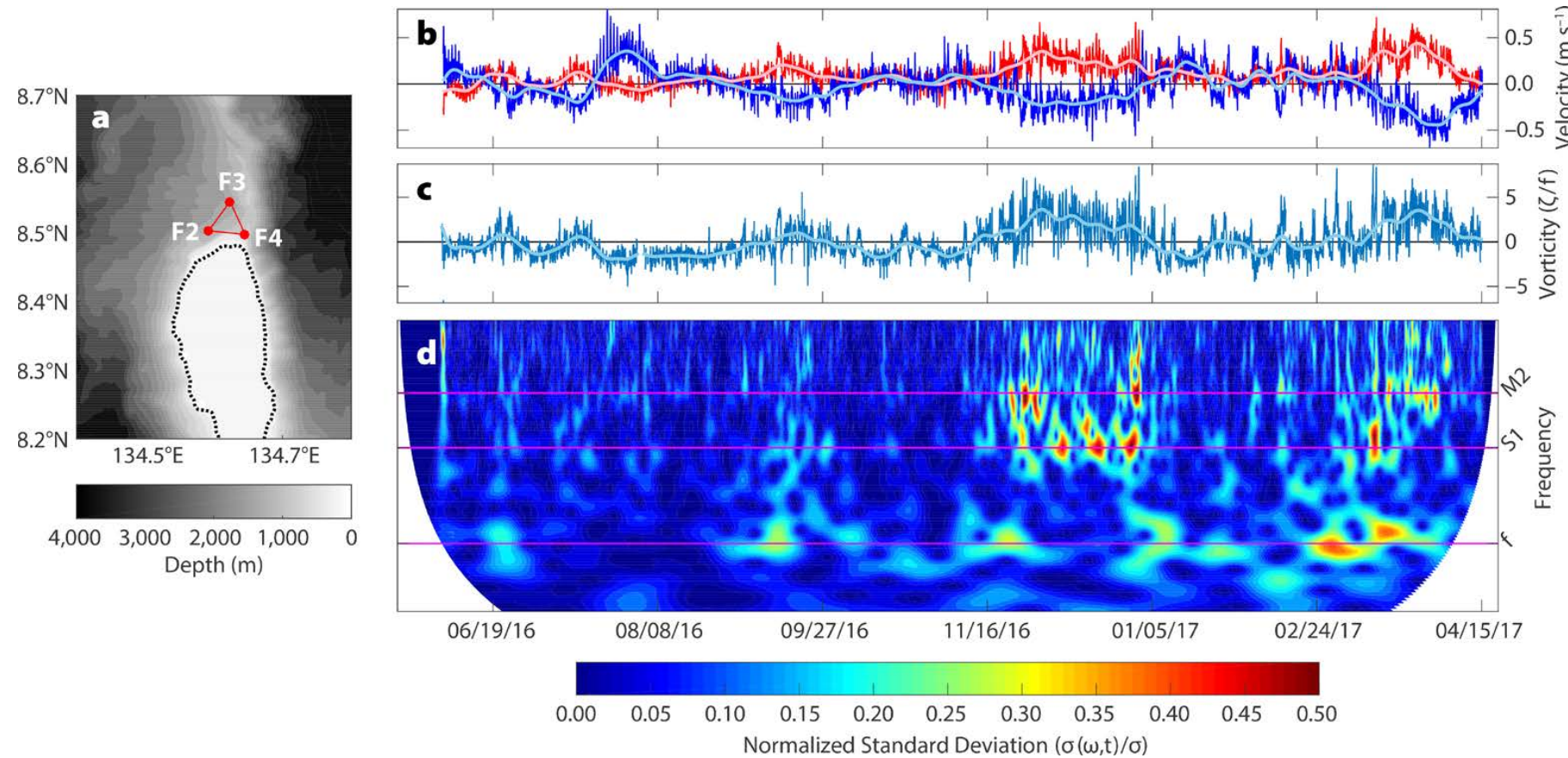

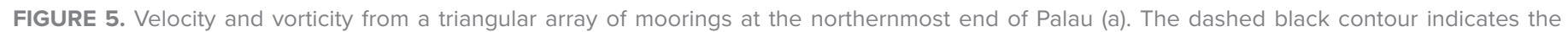

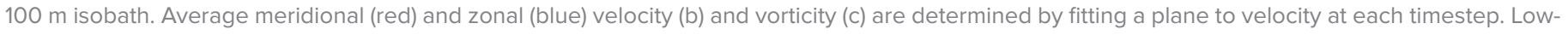

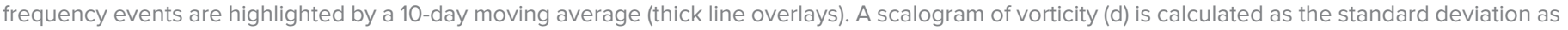

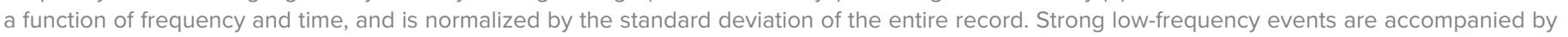
elevated vorticity at higher frequencies, predominantly the semidiurnal (M2) and diurnal tidal frequencies (S1) and the inertial frequency (f). 
limeter. This is the cascade that occurs for three-dimensional flows, when eddies exist in all possible orientations in threedimensional space. The result is that large eddies spawn ever smaller eddies until the eddies are so small that they dissipate. If currents exist only in the horizontal plane, the turbulence is two-dimensional, and the cascade is very different. For two-dimensional turbulence, theory suggests that the variances of vorticity and energy are both conserved, and energy cascades to larger scale (Salmon, 1998). To the extent that the flows we observed are two-dimensional, the small-scale eddies observed near the point could coalesce into larger eddies downstream. This is a process by which the large vorticities in small eddies can be consistent with weaker yet largerscale vorticity in the mean.

The interaction between eddies of different temporal and spatial scales is an issue of ongoing analysis in FLEAT. Addressing this issue would connect large-scale forcing by the general circulation and tides to the high vorticity eddies observed near the point, and to the wake downstream of the island. The processes acting at the island ridge to extract energy and momentum from the large-scale flow would be clarified. An improved quantitative description of these processes could result in better modeling of flow past abrupt topography. Recent examples of modeling vorticity in such flows include work in the California Undercurrent (Molemaker et al., 2015) and in the Gulf Stream (Gula et al., 2016). Continued work to understand vorticity caused by flow past an island, with the FLEAT observations and in future experiments, is essential to forecasting the global, turbulent ocean. @

\section{REFERENCES}

Andres, M., M. Siegelman, V. Hormann, R.C. Musgrave, S.T. Merrifield, D.L. Rudnick, M.A. Merrifield, M.H. Alford, G. Voet, H.W. Wijesekera, and others. 2019. Eddies, topography, and the abyssal flow by the Kyushu-Palau Ridge near Velasco Reef. Oceanography 32(4):46-55, https://doi.org/ 10.5670/oceanog.2019.410.
Gula, J., M.J. Molemaker, and J.C. McWilliams. 2016 Topographic generation of submesoscale centrifugal instability and energy dissipation. Nature Communications 7, https://doi.org/10.1038/ ncomms12811.

Johnston, T.M.S., J.A. MacKinnon, P.L. Colin, P.J. Haley Jr., P.F.J. Lermusiaux, A.J. Lucas, M.A. Merrifield, S.T. Merrifield, C. Mirabito, J.D. Nash, and others. 2019. Energy and momentum lost to wake eddies and lee waves generated by the North Equatorial Current and tidal flows at Peleliu, Palau. Oceanography 32(4):110-125, https://doi.org/10.5670/oceanog.2019.417.

MacKinnon, J.A., M.H. Alford, G. Voet, K. Zeiden, T.M.S. Johnston, M. Siegelman, S. Merrifield, and M. Merrifield. 2019. Eddy wake generation from broadband currents near Palau. Journal of Geophysical Research 124(7):4,891-4,903, https://doi.org/10.1029/2019JC014945.

Molemaker, M.J., J.C. McWilliams, and W.K. Dewar. 2015. Submesoscale instability and generation of mesoscale anticyclones near a separation of the California Undercurrent. Journal of Physical Oceanography 45:613-629, https://doi.org/10.1175/ Jpo-D-13-0225.1.

Pinkel, R. 2012. Velocity imprecision in finitebeamwidth shipboard Doppler sonar: A first-generation correction algorithm. Journal of Atmospheric and Oceanic Technology 29:1,569-1,580, https://doi.org/10.1175/ JTECH-D-12-00041.1.

Roshko, A. 1954. On the Development of Turbulent Wakes from Vortex Streets. National Advisory Committee for Aeronautics Report 1191, 25 pp.

Rudnick, D.L. 2001. On the skewness of vorticity in the upper ocean. Geophysical Research Letters 28:2,045-2,048, https://doi.org/10.1029/ $2000 \mathrm{gl012265.}$

Rudnick, D.L. 2016. Ocean research enabled by underwater gliders. Annual Review of Marine Science 8:519-541, https://doi.org/10.1146/ annurev-marine-122414-033913.

Salmon, R. 1998. Lectures on Geophysical Fluid Dynamics. Oxford University Press, New York, $378 \mathrm{pp}$.

Schönau, M.C., and D.L. Rudnick. 2015. Glider observations of the North Equatorial Current in the western tropical Pacific. Journal of Geophysical Research 120:3,586-3,605, https://doi.org/10.1002/ 2014JC010595.

Schönau, M.C., H.W. Wijesekera, W.J. Teague, P.L. Colin, G. Gopalakrishnan, D.L. Rudnick, B.D. Cornuelle, Z.R. Hallock, and D.W. Wang. 2019. The end of an El Niño: A view from Palau. Oceanography 32(4):32-45, https://doi.org/ 10.5670/oceanog.2019.409.

Shcherbina, A.Y., E.A. D’Asaro, C.M. Lee, J.M. Klymak, M.J. Molemaker, and J.C. McWilliams. 2013. Statistics of vertical vorticity, divergence, and strain in a developed submesoscale turbulence field. Geophysical Research Letters 40:4,706-4,711, https://doi.org/10.1002/grl.50919.

Sherman, J., R.E. Davis, W.B. Owens, and J. Valdes. 2001. The autonomous underwater glider "Spray." IEEE Journal of Oceanic Engineering 26:437-446, https://doi.org/10.1109/48.972076.

Tennekes, H., and J.L. Lumley. 1972. A First Course in Turbulence. The MIT Press, Cambridge, 300 pp.

Zeiden, K.L., D.L. Rudnick, and J.A. Mackinnon. 2019. Glider observations of a mesoscale oceanic island wake. Journal of Physical Oceanography 49(9):2,217-2,235, https://doi.org/ 10.1175/JPO-D-18-0233.1.

\section{ACKNOWLEDGMENTS}

We express our most heartfelt thanks to Terri Paluszkiewicz for her leadership at the Office of Naval Research (ONR). We gratefully acknowledge the support of ONR through grants N00014-15-12488 (DLR, KLZ), N00014-13-1-0480 and N0001415-1-2320 (TMSJ, CO), N00014-15-1-2264 (JAM), N00014-15-1-2592, N00014-15-1- 2264, and N0001416-1-3070 (MHA, GV). Pat and Lori Colin at the Coral Reef Research Foundation provided support that was essential to the success of FLEAT. We thank the Palau National Government for permission to carry out the research in Palau.

\section{AUTHORS}

Daniel L. Rudnick (drudnick@ucsd.edu) is Professor, Kristin L. Zeiden is a graduate student, Celia Y. Ou is a graduate student, T.M. Shaun Johnston is Associate Research Oceanographer, Jennifer A. MacKinnon is Professor, Matthew H. Alford is Professor, and Gunnar Voet is Assistant Project Scientist, all at Scripps Institution of Oceanography, University of California San Diego, La Jolla, CA, USA.

\section{ARTICLE CITATION}

Rudnick, D.L., K.L. Zeiden, C.Y. Ou, T.M.S. Johnston, J.A. MacKinnon, M.H. Alford, and G. Voet. 2019. Understanding vorticity caused by flow passing an island. Oceanography 32(4):66-73, https://doi.org/ 10.5670/oceanog.2019.412.

\section{COPYRIGHT \& USAGE}

This is an open access article made available under the terms of the Creative Commons Attribution 4.0 International License (https://creativecommons.org/ licenses/by/4.0/), which permits use, sharing, adaptation, distribution, and reproduction in any medium or format as long as users cite the materials appropriately, provide a link to the Creative Commons license, and indicate the changes that were made to the original content. 